\title{
Method Optimization Study on Isolation of Volatile Compounds by Headspace Solid-Phase Microextraction (HS-SPME) from Custard Apple (Annona squamosa L.) Pulp.
}

\author{
Mércia de Sousa Galvão ${ }^{1}$, Karen Leticia de Santana ${ }^{2}$, Juliete Pedreira Nogueira², \\ Maria Terezinha Santos Leite Neta ${ }^{2}$, Narendra Narain ${ }^{2 *}$ \\ ${ }^{1}$ Departament of Food Engineering, Federal University of Paraiba, João Pessoa, Brazil \\ ${ }^{2}$ Laboratory of Flavor and Chromatographic Analysis, PROCTA, Federal University of Sergipe, São Cristóvão, Brazil \\ Email: *narendra.narain@gmail.com
}

How to cite this paper: de Sousa Galvão, M., de Santana, K.L., Nogueira, J.P., Neta, M.T.S.L. and Narain, N. (2020) Method Optimization Study on Isolation of Volatile Compounds by Headspace Solid-Phase Microextraction (HS-SPME) from Custard Apple (Annona squamosa L.) Pulp. Journal of Analytical Sciences, Methods and Instrumentation, 10, 59-77.

https://doi.org/10.4236/jasmi.2020.103005

Received: August 10, 2020

Accepted: September 13, 2020

Published: September 16, 2020

Copyright $\odot 2020$ by author(s) and Scientific Research Publishing Inc. This work is licensed under the Creative Commons Attribution International License (CC BY 4.0).

http://creativecommons.org/licenses/by/4.0/

\section{(c) (i) Open Access}

\begin{abstract}
Aroma is an important quality parameter, which can help in delaying degradative processes and hence understanding the volatile compounds that are part of an aroma is extremely important. Thus, the aim of this study was to isolate the volatile compounds present in custard apple (Annona squamosa L.) pulp by solid-phase microextraction (SPME) technique using 3 different fibers (DVB/CAR/PDMS, PDMS and PDMS/DVB). An experimental design was set up to evaluate the best extraction conditions wherein the variables were extraction temperature (minimum $28^{\circ} \mathrm{C}$, maximum $62^{\circ} \mathrm{C}$ ), ionic strength (minimum 0, maximum $30.0 \%$ ) and sample concentration $(\min 1, \max$ 99.0\%). The separation of volatiles was achieved in chromatographic columns of different polarity (polar and non-polar) while identification of volatile compounds was performed by high resolution gas chromatography system coupled with mass spectrometry. The results obtained using 3 different fibers revealed the isolation of 71 compounds with fiber DVB/CAR/PDMS, while only 30 and 21 compounds were isolated using fibers PDMS/DVB and PDMS, respectively. The major classes of compounds identified were terpenes, esters, alcohols and aldehydes. Optimum conditions for obtaining higher number of volatiles for non-polar column were $45^{\circ} \mathrm{C}$ for extraction temperature, $15 \%$ of sodium chloride and $50 \%$ of pulp amount which resulted in isolation of a maximum of 78 peaks.
\end{abstract}

\section{Keywords}

Flavor, SPME, Response Surface Methodology, Volatiles, Gas Chromatography-Mass Spectrometry 


\section{Introduction}

The consumption of tropical and subtropical fruits has been growing worldwide due to their exotic and strong flavor, as well as containing excellent nutritional sources of sugars, vitamins, minerals and other bioactive compounds (organic acids, tannins and others) [1] [2] [3].

The custard apple is a delicate fruit of round form, much appreciated for its pleasant taste and aroma. The fruit contains numerous long, glossy, brown or black bean like seeds covered by a white and sweet custard like pulp, almost without acidity, soft, granulated, perfumed and very tasty. It can be consumed fresh in the form of dessert and is being also used worldwide in large scale as raw material in the productions of ice cream, juices, dairy drinks, nectar among other products [4] [5].

[4] [6] [7] [8] [9] analyzed the volatile compounds of custard apple by Simultaneous Distillation and Extraction (SDE) and liquid-liquid extraction (LLE). However, none of these studies used HS-SPME technique for the isolation of volatiles. The research on the volatile compounds of fruit uses sophisticated and expensive analytical techniques. Moreover, knowledge of these compounds is important, because the fruit is appreciated for its taste and fruit processing generates aroma losses which alters organoleptic quality of the pulp.

Solid-phase microextraction (SPME) is a green sample preparation technique that integrates sampling, isolation, and concentration [10]. SPME technique permits a fast and very attractive extraction for volatile and semi-volatile compounds, being easy to isolate, requiring a small amount of sample, and it has an added advantage of direct application of analyte on to the GC column through thermal desorption whereby sample injection remains solvent and contaminants free [11] [12] [13]. Moreover, SPME offers speed and practicality on the analysis of authentic chemical constituents of fruit flavor [14].

The SPME technique efficiency depends on the polarity and thickness of the fiber coating, the extraction time and temperature, the agitation and $\mathrm{pH}$ of the sample solution, the addition of salt to the sample, and on the concentration of analyte in a sample [15]. Therefore, several studies about fruits and juices have been dedicated to the optimization of SPME parameters for volatile compounds isolation from jambolan fruits [16], Korla pear juice [17], soursop pulp [18] [19], berry [20], and blackberry fruits [21]. Response Surface Methodology (RSM) is a tool for multivariate optimization commonly used for HS-SPME optimization. It requires less effort and resources than those involved in univariate procedures, once fewer experimental runs are needed; hence less time is spent to achieve the same goal [22] [23].

In relation to published articles about custard apple, there is little work done in identifying its volatile compounds. However, no work has yet been reported and none of these used the technique of SPME. Thus, this study was designed to perform various experiments by varying the extraction parameters, such as use of different coatings of fiber, varying extraction temperature, ionic strength and 
sample concentration in order to obtain extracts of a large number of volatile compounds as well as to evaluate their effects on isolation of volatile compounds from custard apple pulp so that the analytical conditions could be optimized for determination of volatile constituents of custard apple fruit pulp, emphasizing on their character impact compounds.

\section{Material and Methods}

\subsection{Sample and Chemical Standards}

Custard apple (Annona squamosa L.) fruits were acquired from Central Market, situated in city of Aracaju ( $\left.10^{\circ} 54^{\prime} 30.9^{\prime \prime S}, 37^{\circ} 03^{\prime} 41.0^{\prime \prime} \mathrm{W}\right)$ in Northeast region of Brazil. These fruits were washed with chlorinated water (10 ppm of available chlorine) at laboratory, followed by washing in running water and later only ripe fruits were selected for this study. The classification of ripe fruit was based on its total soluble solids content which was $21.0^{\circ} \mathrm{Brix}$, and its titratable acidity value was $0.3 \%$ citric acid. In a blender (Waring blender 70115, Model WF2211214), the pulp was extracted for $2 \mathrm{~min}$ and stored in airtight containers at $-18^{\circ} \mathrm{C}$. The pulp was thawed at room temperature $\left(28^{\circ} \mathrm{C} \pm 3^{\circ} \mathrm{C}\right)$ before analysis.

The chemical standards (purity 99.9\%), positively identified in this study, were purchased from Sigma/Aldrich (San Diego, USA), while the solvents utilized were purchased from Merck (Brazil).

\subsection{Sample Preparation and SPME}

The volatile components present in ripe custard apple fruit pulp were isolated by SPME technique and separated by high resolution gas chromatography. Initially, three different fibers, purchased from Supelco, Bellefonte, PA, USA-30 $\mu$ m polydimethylsiloxane (PDMS), 50/30 $\mu \mathrm{m}$ divinyl benzene/carboxen/polydimethylsiloxane (DVB/CAR/PDMS) and $65 \mu \mathrm{m}$ polydimethylsiloxane/divinylbenzene (PDMS/ DVB) - were tested to analyze their performance in extraction of volatiles from custard apple pulp.

The extraction conditions used for the selection of fiber were those recommended [8]. Three grams of pulp was diluted in $10 \mathrm{~mL}$ of water in $40 \mathrm{~mL}$ vial. Before each extraction the vial was placed in a water bath $\left(40^{\circ} \mathrm{C}\right)$ under magnetic stirring for $15 \mathrm{~min}$ (equilibrium time). Later the SPME fiber was inserted in the headspace of the solution for adsorption of volatiles for 30 minutes. After this exposure, the fiber was removed and later introduced into the injector of gas chromatograph (Varian, Model 4000) for thermal desorption of volatiles for 7 minutes. The $\mathrm{pH}$ used was the natural $\mathrm{pH}$ (5.3) of the fruit pulp.

After screening of fibers by headspace extraction efficiency of volatile compounds, a factorial design of $2^{3}$ including 6 axial points and six repetitions at the central point amounting to a total of 20 experiments were performed. The central composite design (CCD) matrix shows the coded and actual values of different variables in Table 1 . The influence of extraction temperature (minimum $28^{\circ} \mathrm{C}$, maximum $62^{\circ} \mathrm{C}$ ), amount of salt ionic strength (minimum 0 , maximum 
Table 1. Coded independent variables and their actual values in the experimental design.

\begin{tabular}{|c|c|c|c|c|c|c|}
\hline \multirow{2}{*}{$\begin{array}{l}\text { Experiment } \\
\text { Number }\end{array}$} & \multicolumn{3}{|c|}{ Coded variables } & \multicolumn{3}{|c|}{ Actual values } \\
\hline & $X_{1}$ & $X_{2}$ & $X_{3}$ & $\begin{array}{c}\text { Extraction } \\
\text { temperature }\left({ }^{\circ} \mathrm{C}\right)\end{array}$ & $\begin{array}{l}\mathrm{NaCl} \\
(\%)\end{array}$ & $\begin{array}{l}\text { Pulp amount } \\
\text { (\%) }\end{array}$ \\
\hline 1 & -1 & -1 & -1 & 35 & 6 & 21 \\
\hline 2 & +1 & -1 & -1 & 55 & 6 & 21 \\
\hline 3 & -1 & +1 & -1 & 35 & 24 & 21 \\
\hline 4 & +1 & +1 & -1 & 55 & 24 & 21 \\
\hline 5 & -1 & -1 & +1 & 35 & 6 & 79 \\
\hline 6 & +1 & -1 & +1 & 55 & 6 & 79 \\
\hline 7 & -1 & +1 & +1 & 35 & 24 & 79 \\
\hline 8 & +1 & +1 & +1 & 55 & 24 & 79 \\
\hline 9 & -1.68 & 0 & 0 & 28 & 15 & 50 \\
\hline 10 & +1.68 & 0 & 0 & 62 & 15 & 50 \\
\hline 11 & 0 & -1.68 & 0 & 45 & 0 & 50 \\
\hline 12 & 0 & +1.68 & 0 & 45 & 30 & 50 \\
\hline 13 & 0 & 0 & -1.68 & 45 & 15 & 1 \\
\hline 14 & 0 & 0 & +1.68 & 45 & 15 & 99 \\
\hline 15 & 0 & 0 & 0 & 45 & 15 & 50 \\
\hline 16 & 0 & 0 & 0 & 45 & 15 & 50 \\
\hline 17 & 0 & 0 & 0 & 45 & 15 & 50 \\
\hline
\end{tabular}

$30.0 \%)$ and the sample concentration (min $1, \max 99.0 \%$ ) on volatiles isolation was evaluated. Equilibrium and extraction times were previously defined.

\subsection{GC-MS Conditions}

The separation was performed using a gas chromatography system (Varian Inc. Walnut Creek, California, USA) equipped with mass spectrometer (Model 4000). The chromatographic conditions were according to the methodology described earlier by [24]. The analysis was performed in a Varian Factor Four Capillary VF-5ms analytical column $(30 \mathrm{~m} \times 0.25 \mathrm{~mm}$ i.d. $\times 0.25 \mathrm{~mm}$ film thickness; component: $5 \%$ diphenyl and 95\% dimethylpolysiloxane), and CP-Wax52 $\mathrm{CB}$ analytical column $(30 \mathrm{~m} \times 0.25 \mathrm{~mm}$ i.d. $\times 0.25 \mathrm{~mm}$ film thickness; component: polyethylene glycol). The injector temperature was held at $220^{\circ} \mathrm{C}$. Helium (99.9999\%) was used as a carrier gas at a flow rate of $1.0 \mathrm{~mL} \cdot \mathrm{min}^{-1}$. The mass spectrometer was operated in the electron ionization mode with an electrical energy of $70 \mathrm{eV}$ and an ion source temperature of $250^{\circ} \mathrm{C}$. The mass spectrum was scanned between 33 and 450 amu at 0.3 s interval.

\subsection{Compounds Identification}

The linear retention index (RI) values for unknowns were determined based on 
retention time data obtained by analyzing a series of normal alkanes $\left(\mathrm{C}_{8}-\mathrm{C}_{21}\right)$. Volatile components were positively identified by matching their RI values and mass spectra with those of standards, also run under identical chromatographic conditions in the laboratory [19].

The identification was also based on matching an unknown mass spectrum with a spectrum available on the National Institute of Standards and Technology [25] mass spectral data system or from the literature [26] [27] [28].

\subsection{Data Analysis}

The Response Surface Methodology (RSM) of results was conducted using the software, Statistica ${ }^{\mathrm{TM}}$ Trial (TIBCO Software Inc., Palo Alto, CA, USA) for the estimation of regression coefficients and the second order polynomial model for Equation (1). The Analysis of Variance (ANOVA) of the data was performed to evaluate the adequacy and the significance of the regression model. The multiple regression coefficients were calculated for using the Method of Least Square (MLS).

$$
Y=\beta_{0}+\sum_{i=1}^{k} \beta_{i} X_{i}+\sum_{i=1}^{k} \beta_{i i} X_{i}^{2}+\sum_{i \neq j=1}^{k} \beta_{i j} X_{i} X_{j}
$$

where $Y$ is the dependent variable (number of peaks), $X_{i}$ and $X_{j}$ are the independent variables, $\beta_{0}$ is the coefficient constant, $\beta_{i}$ is the linear coefficients, $\beta_{i i}$ is the quadratic coefficients and $\beta_{i j}$ is coefficient for interaction, and $\mathrm{k}$ is the number of tested variables $(k=3)$.

ANOVA and Tukey's test were used to determine significant differences ( $\mathrm{p} \leq$ 0.05 ) among the fiber coatings by software SAS University Edition (Statistical Analysis System Institute, Cary, NC, USA). Moreover for the validation of the model, the observed value was compared with predicted value by calculation of coefficient of variation (CV).

\section{Results and Discussion}

\subsection{SPME Fiber Selection}

Initially, preliminary tests were conducted using 3 different SPME fibers (50/30 $\mu \mathrm{m}$ DVB/CAR/PDMS, $30 \mu \mathrm{m}$ PDMS and $65 \mu \mathrm{m}$ PDMS/DVB) using custard apple pulp so as to evaluate the performance and effectiveness of each coating material on the headspace extraction efficiency of volatile compounds. The data on number of peaks and other details obtained on volatiles isolated by using different fibers in SPME are presented in Table 2. The fibers DVB/CAR/PDMS, PDMS and PDMS/DVB managed to isolate 71, 21 and 30 compounds, respectively. The major classes of compounds were terpenes (>90\%). DVB/CAR/PDMS fiber was the most efficient for extracting 71 compounds and hence this fiber was selected to conduct further experiments. However, most of the work published [4] [6] [7] [8] [9] on custard apple volatiles reports the predominant class being esters followed by terpenes. 
Table 2. Number of volatile compounds identified in custard apple pulp isolated by different fibers used in SPME technique.

\begin{tabular}{cccc}
\hline Characteristics & $50 / 30 \mu \mathrm{m}$ DVB/CAR/PDMS & $65 \mu \mathrm{m}$ PDMS/DVB & $30 \mu \mathrm{m}$ PDMS \\
\hline Number of peaks & 71 & 30 & 21 \\
No. of identified compounds & $59(97.34 \%)$ & $26(99.11 \%)$ & $18(96.81 \%)$ \\
No. of aldehydes identified & $5(0.34 \%)$ & $0(0.00 \%)$ & $0(0.00 \%)$ \\
No. of alcohols identified & $3(0.44 \%)$ & $0(0.00 \%)$ & $0(0.00 \%)$ \\
No. of esters identified & $5(0.96 \%)$ & $1(1.12 \%)$ & $1(1.62 \%)$ \\
No. of terpenes identified & $42(95.42 \%)$ & $25(97.99 \%)$ & $17(95.19 \%)$ \\
No. of other compounds & $4(0.18 \%)$ & $0(0.00 \%)$ & $0(0.00 \%)$ \\
\hline
\end{tabular}

Semi-polar fiber coating (DVB/CAR/PDMS) appeared to be most efficient in separating 71 volatile compounds in the custard apple compared to bipolar fiber coating (PDMS/DVB) that extracted only 21 volatile compounds while non-polar fiber coating (PDMS) extracted 30 volatile compounds.

Thus DVB/CAR/PDMS fiber showed the best performance, allowing the separation of larger number of chromatogram peaks. Due to these results, DVB/CAR/POMS fiber was utilized for all experiments that followed these preliminary trials.

Several types of coated fibers are available and no single fiber coating will extract all analytes to the same extent. Were reported CAR/PDMS fiber to be the most appropriate fiber coating to extract small molecules and acids [29] [30]. In general, polar fibers are expected to be effective for extracting polar analytes and nonpolar fibers for extracting nonpolar analytes [31]. Thus, DVB/CAR/PDMS fiber has intermediary polarity and thus is able to extract compounds with different polarities [31]. In our work it showed to extract better the terpenic compounds and by far showed the best performance (Figure 1 and Figure 2).

Were tested 4 different coatings (PDMS, CW/DVB, CAR/PDMS and PA) in fibers to extract volatile compounds by SPME in soursop pulp and reported that the most efficient fiber was PDMS which isolated 16 compounds [32]. They also reported that the largest extraction capacity in area count and isolation of lighter compounds from soursop pulp was obtained by using CAR/PDMS fiber. However, the fruit used in their work was soursop (Annona muricata L.) while this study was performed with custard apple (Annona reticulata L.) pulp and according to those researchers most of the compounds belongs to the class of esters $(50 \%)$.

When comparing different fibers used in this work it was found that there were no significant differences between the chemical classes of the extracted compounds where the principal class was of terpenes followed by esters and aldehydes.

The most recent work done on the custard apple volatile is by [4]. Other prominent works who also used the custard apple, coming from Amazon region 

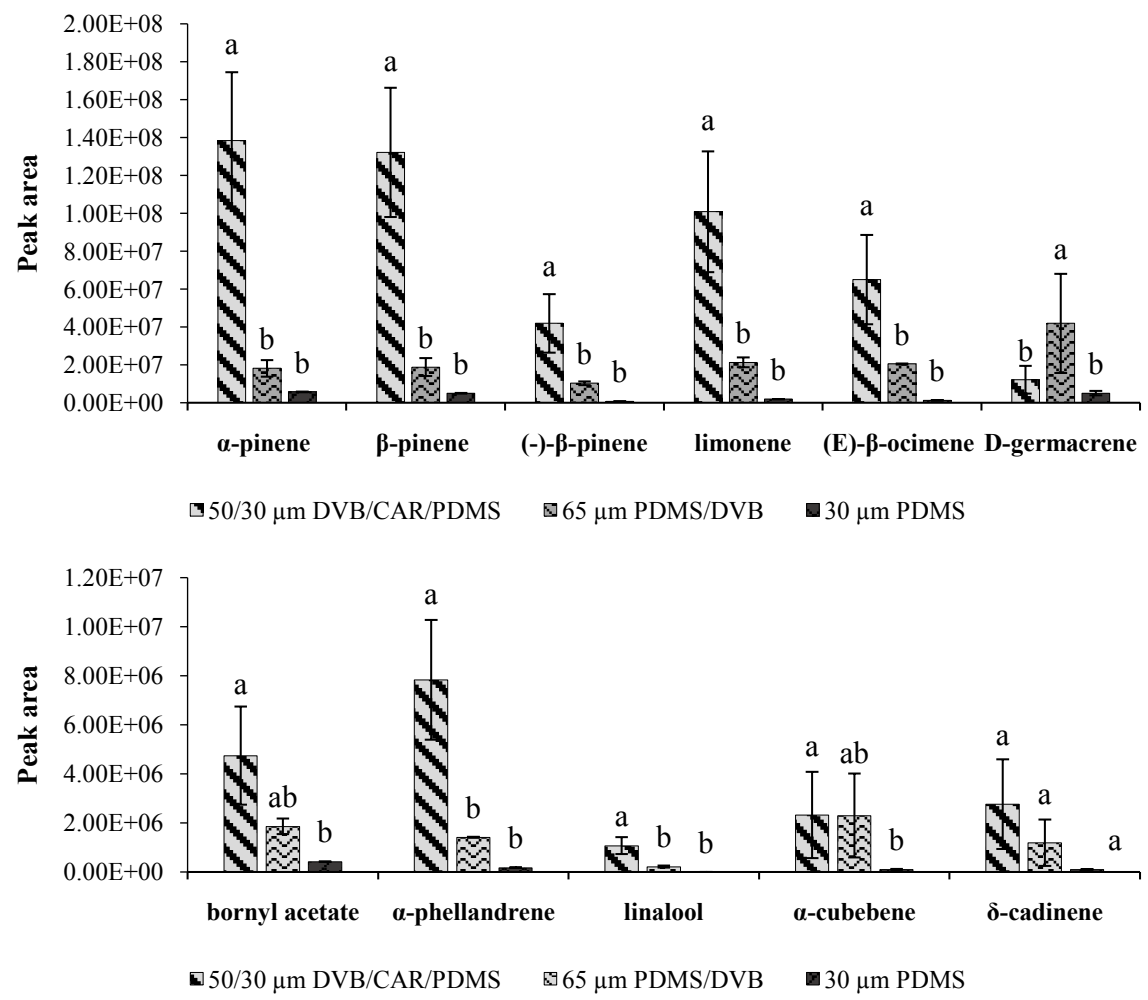

Figure 1. Influence of different SPME fibers on the area of some isolated volatile compounds from custard apple pulp.

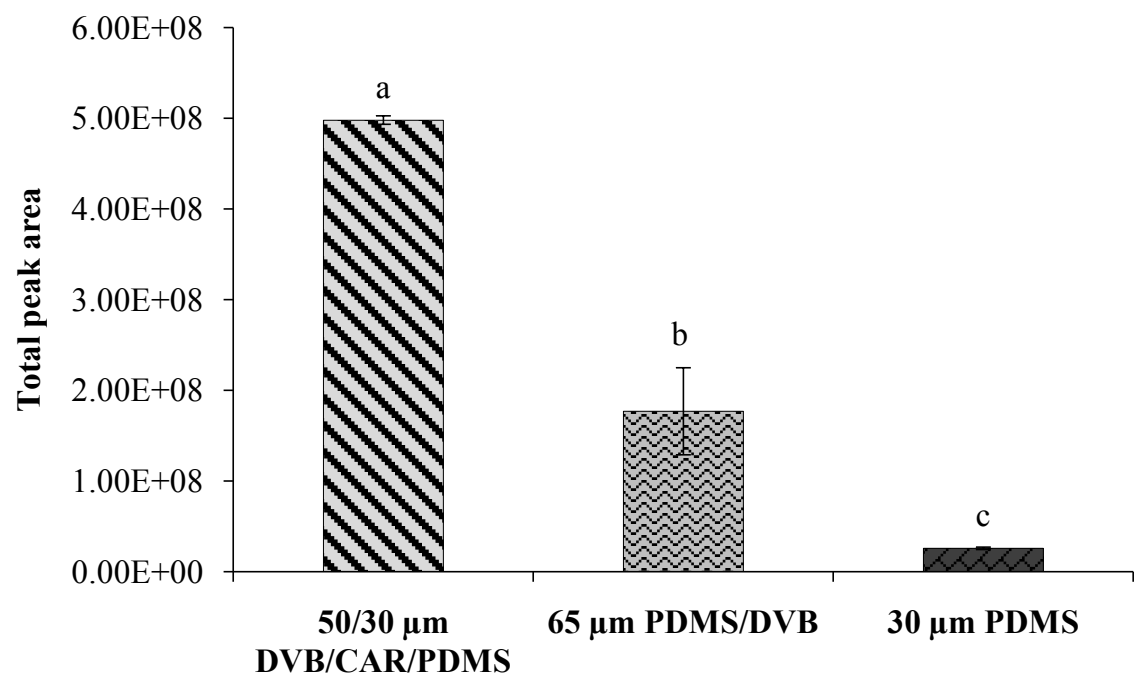

Figure 2. Efficiency of SPME fiber coatings on the extraction of volatile compounds from custard apple pulp. Footnote: (Values are means of three independent determination, $\mathrm{n}=$ $3)$.

of Brazil [6]. Two other prominent works were those who used fruit from Asia, and who analyzed fruits from France. In these publications the esters were the main compounds, followed by terpenes [7] [8].

Table 3 presents data on volatile compounds identified in custard apple pulp using SPME with three different fibers. The main isolated volatile compounds 
Table 3. Volatile compounds identified in custard apple pulp captured by using different fibers in SPME.

\begin{tabular}{|c|c|c|c|c|c|c|c|c|}
\hline \multirow{2}{*}{ Compounds } & \multirow{2}{*}{$\mathrm{RI}_{\text {non-polar }}{ }^{\mathrm{a}}$} & \multicolumn{2}{|c|}{$50 / 30 \mu \mathrm{m}$ DVB/CAR/PDMS } & \multicolumn{2}{|c|}{$65 \mu \mathrm{m}$ PDMS/DVB } & \multicolumn{2}{|c|}{$30 \mu \mathrm{m}$ PDMS } & \multirow{2}{*}{ Odor note } \\
\hline & & $\mathrm{RI}^{\mathrm{b}}$ & Area $\%(S D)^{c}$ & $\mathrm{RI}^{\mathrm{b}}$ & Area $\%(S D)^{c}$ & $\mathrm{RI}^{\mathrm{b}}$ & Area $\%(S D)^{c}$ & \\
\hline \multicolumn{9}{|l|}{ Aldehydes } \\
\hline acetaldehyde & 412 & $<600$ & $0.13(0.05)$ & & ND & & ND & Pungent, ether ${ }^{6}$ \\
\hline butanal & 574 & $<600$ & $0.05(0.02)$ & & ND & & ND & Pungent, green ${ }^{6,7}$ \\
\hline 3-methyl-butanal & 628 & 621 & $0.07(0.05)$ & & ND & & ND & $\begin{array}{c}\text { Ethereal aldehydic, peach, } \\
\text { chocolate, fatty }{ }^{6,7}\end{array}$ \\
\hline 2-methyl-butanal & 640 & 630 & $0.06(0.03)$ & & ND & & ND & Cocoa, almond ${ }^{6}$ \\
\hline benzaldehyde & 964 & 963 & $0.03(0.00)$ & & ND & & ND & Almond, burnt, sugar ${ }^{6,7}$ \\
\hline Total & & & 0.34 & & & & & \\
\hline \multicolumn{9}{|l|}{ Alcohols } \\
\hline ethanol & 705 & 696 & $0.05(0.01)$ & & ND & & ND & Sweet $^{6}$ \\
\hline 3-methyl-1-butanol & 804 & 804 & $0.05(0.03)$ & & ND & & ND & Whiskey, malt ${ }^{6}$ \\
\hline (Z)-3-hexenol & 1286 & 1287 & $0.80(0.13)$ & & ND & & ND & Grass $^{6}$ \\
\hline Total & & & 0.44 & & & & & \\
\hline \multicolumn{9}{|l|}{ Esters } \\
\hline methyl butanoate & 705 & 696 & $0.05(0.01)$ & & ND & & ND & Ether, fruit, sweet ${ }^{6}$ \\
\hline ethyl butanoate & 804 & 804 & $0.05(0.03)$ & & ND & & ND & Apple $^{6}$ \\
\hline methyl (E)-2-hexenoate & 966 & 968 & $0.04(0.01)$ & & ND & & ND & Ester, fruity ${ }^{7}$ \\
\hline bornyl acetate $e^{1-4}$ & 1286 & 1287 & $0.80(0.13)$ & 1287 & $1.12(0.18)$ & 167 & $1.62(0.10)$ & $\begin{array}{l}\text { Woody, camphoreous, } \\
\text { mentholic, woody }{ }^{6,7}\end{array}$ \\
\hline $\begin{array}{c}(E) \text {-hex-3-enyl } \\
(E) \text {-2-methylbut-2-enoate }\end{array}$ & 1319 & 1326 & $0.01(0.00)$ & & ND & & ND & Green, earthy ${ }^{6,7}$ \\
\hline Total & & & 0.96 & & 1.12 & & 1.62 & \\
\hline \multicolumn{9}{|l|}{ Terpenes } \\
\hline tricyclene & 924 & 923 & $0.02(0.01)$ & & ND & & ND & NA \\
\hline$\alpha$-thujene & 929 & 929 & $0.83(0.03)$ & 930 & $0.38(0.27)$ & 930 & $0.36(0.07)$ & Woody, green, herb ${ }^{6,7}$ \\
\hline$\alpha$-pinene ${ }^{1-5}$ & 938 & 935 & $24.48(2.15)$ & 934 & $12.34(8.51)$ & 934 & $22.80(2.57)$ & Pine, turpentine ${ }^{6,7}$ \\
\hline camphene $\mathrm{e}^{1,2,4}$ & 953 & 950 & $1.04(0.12)$ & 950 & $0.45(0.32)$ & 950 & $0.92(0.15)$ & Camphor ${ }^{6,7}$ \\
\hline$\beta$-thujene & 966 & & ND & 976 & $0.50(0.34)$ & 976 & $0.37(0.01)$ & $\begin{array}{l}\text { Cooling, woody, piney, } \\
\text { minty, eucalyptus }\end{array}$ \\
\hline$\beta$-pinene e $^{1-3,5}$ & 978 & 979 & $23.36(1.91)$ & 980 & $12.80(8.97)$ & 980 & $19.74(2.32)$ & Pine, resin, turpentine $e^{6,7}$ \\
\hline$(-)-\beta$-pinene & 993 & 992 & $7.18(0.54)$ & 992 & $6.75(3.47)$ & 992 & $2.72(0.03)$ & NA \\
\hline$\alpha$-phellandrene ${ }^{1,3}$ & 1006 & 1005 & $1.37(0.07)$ & 1004 & $0.90(0.37)$ & 1004 & $0.66(0.03)$ & Turpentine, mint, spice $e^{6,7}$ \\
\hline 2 -carene & 1019 & 1016 & $0.20(0.17)$ & & ND & & ND & NA \\
\hline$p$-cymene $e^{1-3}$ & 1024 & & ND & 1024 & $0.29(0.21)$ & & ND & Pleasant odor ${ }^{6,7}$ \\
\hline limonene $e^{1,2,4,5}$ & 1028 & 1028 & $17.54(0.25)$ & 1028 & $14.02(7.71)$ & 1028 & $7.71(0.22)$ & Citrus, mint $^{6,7}$ \\
\hline eucaliptol & 1035 & & ND & 1030 & $0.84(0.40)$ & 1030 & $1.19(0.20)$ & $\begin{array}{l}\text { Eucalyptus, herbal, cam- } \\
\text { phor }^{6,7}\end{array}$ \\
\hline
\end{tabular}




\section{Continued}

\begin{tabular}{|c|c|c|c|c|c|c|c|c|}
\hline$\alpha$-phellandrene $e^{1,3}$ & 1006 & 1005 & $1.37(0.07)$ & 1004 & $0.90(0.37)$ & 1004 & $0.66(0.03)$ & Turpentine, mint, spice $e^{6,7}$ \\
\hline 2-carene & 1019 & 1016 & $0.20(0.17)$ & & ND & & ND & NA \\
\hline$p$-cymene ${ }^{1-3}$ & 1024 & & ND & 1024 & $0.29(0.21)$ & & ND & Pleasant odor ${ }^{6,7}$ \\
\hline limonene $e^{1,2,4,5}$ & 1028 & 1028 & $17.54(0.25)$ & 1028 & $14.02(7.71)$ & 1028 & $7.71(0.22)$ & Citrus, $\operatorname{mint}^{6,7}$ \\
\hline eucaliptol & 1035 & & ND & 1030 & $0.84(0.40)$ & 1030 & $1.19(0.20)$ & $\begin{array}{l}\text { Eucalyptus, herbal, } \\
\text { camphor }^{6,7}\end{array}$ \\
\hline$(Z)-\beta$-ocimene ${ }^{1,2,4}$ & 1039 & 1035 & $0.39(0.02)$ & 1034 & $0.27(0.14)$ & & ND & Sweet, herb ${ }^{6,7}$ \\
\hline (E)- $\beta$-ocimene $e^{1-4}$ & 1050 & 1046 & $11.15(0.76)$ & 1046 & $13.01(4.94)$ & 1046 & $5.08(0.37)$ & Herb $^{6,7}$ \\
\hline$\gamma$-terpinene & 1061 & 1057 & $0.36(0.00)$ & 1057 & $0.20(0.10)$ & & ND & Gasoline, turpentine $e^{6,7}$ \\
\hline$(E)$-sabinene hydrate ${ }^{3}$ & 1070 & 1066 & $0.14(0.01)$ & 1066 & $0.11(0.02)$ & & ND & Lemon, $\operatorname{resin}^{6,7}$ \\
\hline terpinolene $e^{1-4}$ & 1083 & 1090 & $0.28(0.02)$ & 1089 & $0.19(0.09)$ & & ND & Sweet, fresh, piney, citrus ${ }^{6,7}$ \\
\hline linalool $^{1,2,4,5}$ & 1098 & 1101 & $0.19(0.01)$ & 1102 & $0.13(0.01)$ & & ND & Flower, lavender ${ }^{6,7}$ \\
\hline p-mentha-1,3,8-triene & 1119 & 1122 & $0.04(0.01)$ & & ND & & ND & Turpentine $^{6,7}$ \\
\hline$(E, E)$-cosmene & 1130 & 1130 & $0.23(0.01)$ & & ND & & ND & NA \\
\hline allo-ocimene & 1144 & 1140 & $0.19(0.03)$ & & ND & & ND & NA \\
\hline neo-allo-ocimene & 1131 & 1145 & $0.03(0.03)$ & & ND & & ND & NA \\
\hline pinocarvone $e^{2,4}$ & 1164 & 1164 & $0.01(0.00)$ & & ND & & ND & NA \\
\hline terpinen-4-ol & 1177 & 1178 & $0.01(0.00)$ & & ND & & ND & Turpentine, nutmeg, must ${ }^{6}$ \\
\hline$\alpha$-terpineol & 1189 & 1192 & $0.02(0.01)$ & & ND & & ND & Oil, anise, $\operatorname{mint}^{6}$ \\
\hline$\alpha$-thujenal & 1190 & 1200 & $0.01(0.00)$ & & ND & & ND & Woody, green, herb ${ }^{6,7}$ \\
\hline$\alpha$-cubebene $\mathrm{e}^{1,3,5}$ & 1349 & 1350 & $0.36(0.23)$ & 1349 & $1.15(0.96)$ & 1349 & $0.38(0.09)$ & Herbal, waxy ${ }^{6,7}$ \\
\hline$\alpha$-ylangene & 1370 & 1372 & $0.01(0.01)$ & & ND & & ND & NA \\
\hline$\alpha$-copaene $e^{1-3,5}$ & 1378 & 1377 & $0.70(0.39)$ & 1376 & $2.36(1.93)$ & 1377 & $1.13(0.28)$ & NA \\
\hline caryophyllene $e^{1,2,4,5}$ & 1419 & 1420 & $0.45(0.26)$ & 1419 & $1.65(1.35)$ & 1419 & $0.84(0.07)$ & Wood, spice ${ }^{6,7}$ \\
\hline aromandendrene $e^{1,5}$ & 1447 & 1439 & $0.24(0.15)$ & & ND & & ND & NA \\
\hline (Z)-muurola-3,5-diene & 1450 & 1451 & $0.01(0.01)$ & & ND & & ND & NA \\
\hline humulene $e^{1,2,4}$ & 1455 & 1454 & $0.06(0.04)$ & 1453 & $0.24(0.21)$ & & ND & Wood $^{6,7}$ \\
\hline (Z)-muurola-4(14),5-diene & 1470 & 1463 & $0.05(0.03)$ & & ND & & ND & NA \\
\hline$\gamma$-muurolene & 1477 & 1477 & $0.30(0.21)$ & 1477 & $0.65(0.51)$ & 1477 & $0.21(0.04)$ & Herb, wood, spice ${ }^{6,7}$ \\
\hline D-germacrene $e^{1,2,4,5}$ & 1485 & 1481 & $1.95(0.79)$ & 1481 & $20.06(11.29)$ & 1481 & $19.60(4.95)$ & Wood, spice ${ }^{6,7}$ \\
\hline $\begin{array}{c}\text { (+)-epi-bi-cyclosesqui-phellan } \\
\text { drene }\end{array}$ & 1490 & 1492 & $0.01(0.01)$ & & ND & & ND & NA \\
\hline$\gamma$-elemene & 1492 & 1497 & $1.47(0.61)$ & 1497 & $7.84(3.71)$ & 1497 & $11.62(1.45)$ & Fruity, dry ${ }^{6,7}$ \\
\hline$\alpha$-muurolene & 1505 & 1501 & $0.07(0.04)$ & & ND & & ND & Wood $^{6,7}$ \\
\hline$(-)$ - $\beta$-cadinene & 1518 & 1508 & $0.02(0.01)$ & & ND & & ND & NA \\
\hline$\gamma$-cadinene ${ }^{5}$ & 1513 & 1514 & $0.15(0.09)$ & 1514 & $0.20(0.19)$ & & ND & Wood $^{6,7}$ \\
\hline$\delta$-cadinene $e^{2-5}$ & 1523 & 1524 & $0.44(0.22)$ & 1524 & $0.58(0.55)$ & 1524 & $0.38(0.07)$ & Thyme, medicine, wood ${ }^{6,7}$ \\
\hline cadine-1,4-diene & 1533 & 1532 & $0.02(0.01)$ & & ND & & ND & NA \\
\hline
\end{tabular}




\section{Continued}

\begin{tabular}{|c|c|c|c|c|c|c|}
\hline$\alpha$-cadinene & 1538 & 1537 & $0.03(0.02)$ & ND & $\mathrm{ND}$ & NA \\
\hline$\alpha$-calacorene & 1542 & 1542 & $0.01(0.01)$ & ND & ND & Wood $^{6}$ \\
\hline Total & & & 95.42 & 97.99 & 95.19 & \\
\hline \multicolumn{7}{|l|}{ Others } \\
\hline 2,4,5-trimethyl-1,3-dioxolane & 710 & 702 & $0.05(0.05)$ & ND & ND & NA \\
\hline 1-methylpyrrol ${ }^{3}$ & 737 & 718 & $0.08(0.04)$ & ND & $\mathrm{ND}$ & NA \\
\hline styrene & 891 & 892 & $0.04(0.02)$ & ND & $\mathrm{ND}$ & Balsamic $^{6}$ \\
\hline bicyclo[3.2.0]hepta-2,6-diene & NA & 1402 & $0.01(0.01)$ & ND & $\mathrm{ND}$ & NA \\
\hline Total & & & 0.18 & & & \\
\hline
\end{tabular}

${ }^{\mathrm{a}} \mathrm{RI}_{\text {non-polar }}$ Linear Retention index from literature (NIST 2011). ${ }^{\mathrm{b}}$ Linear Retention index on VF-5ms obtained experimentally. ${ }^{\mathrm{c}} \mathrm{Values}$ are expressed as Means (Standard Deviation). NA - Not available. ND - Not detected. ${ }^{1}$ [9] related to SDE in Australian fruit pulp. ${ }^{2}$ [7] related to hydrodistillation in essential oil of French fruit pulp. ${ }^{3}[8]$ related to SDE in Malaysian fruit pulp. ${ }^{4}[6]$ related to SDE in essential oil of Brazilian custard apple. ${ }^{5}[4]$ related to LLE in Indian custard apple pulp. ${ }^{6,7}[33]$ [34].

from custard apple pulp by different fibers and their relative peak area variation were: $\alpha$-pinene (24.48\% to $12.34 \%) ; \beta$-pinene (23.36\% to $12.80 \%$ ); D-germacrene (20.06\% to $1.95 \%)$; limonene (17.54\% to $7.71 \%)$; $(E)$ - $\beta$-ocimene $(13.01 \%$ to $5.08 \%) ; \lambda$-elemene (11.62\% to $1.47 \%)$; and (-)- $\beta$-pinene (7.18\% to $2.72 \%)$.

\subsection{Experimental Design}

According to the experimental design (Table 1) which varied the key operational parameters for extraction (extraction temperature, sodium chloride amount and pulp amount) in SPME, the predicted and obtained data on the number of peaks on non-polar column and the obtained data on the number of peaks on polar column are presented in Table 4.

After the selection of the DVB/CAR/PDMS fiber, a new experimental design was applied which evaluated the influence of sample concentration in the volatile composition of custard apple pulp. In these experiments on custard apple pulp, the larger number of peaks on non-polar column was observed in the extraction conditions of central point (extraction temperature of $45^{\circ} \mathrm{C}, \mathrm{NaCl}$ concentration of $15 \%$, and $50 \%$ of pulp amount) while the larger number of peaks on polar column was detected in experimenter run 6 (extraction temperature of $55^{\circ} \mathrm{C}, \mathrm{NaCl}$ concentration of $6 \%$, and $79 \%$ of pulp amount). The experimental error was calculated for the values taken into consideration of three replicates of central point. The relative standard deviations equal to $6.87 \%$ and $7.12 \%$ showed that the extraction of volatile compounds from apple custard pulp by SPME technique had a good repeatability on both the non-polar and polar columns.

In Pareto chart (Figure 3(a)), the linear and quadratic effects of pulp amount, and quadratic effects of extraction temperature and salt amount were significant $(\mathrm{p} \leq 0.05)$. The linear effects of extraction temperature and salt amount were not significant at the $5 \%$ significance level, but they were significant at the $10 \%$ significance level while their interactions were not significant $(\mathrm{p}>0.10)$. The increase in extraction temperature, in salt amount added and in concentration of 
Table 4. Number of volatile compounds present in custard apple pulp isolated by SPME and separated by GC on non-polar and polar columns.

\begin{tabular}{|c|c|c|c|c|c|c|c|}
\hline \multirow{3}{*}{$\begin{array}{l}\text { Experiment } \\
\text { number }\end{array}$} & \multicolumn{3}{|c|}{ Independent Variables } & \multicolumn{4}{|c|}{ Dependent Variables } \\
\hline & \multirow{2}{*}{$\begin{array}{l}\text { Extraction } \\
\text { temperature } \\
\left({ }^{\circ} \mathrm{C}\right)\end{array}$} & \multirow{2}{*}{$\begin{array}{c}\mathrm{NaCl} \\
(\%)\end{array}$} & \multirow{2}{*}{$\begin{array}{l}\text { Pulp } \\
\text { amount } \\
(\%)\end{array}$} & \multicolumn{3}{|c|}{$\begin{array}{l}\text { Number of peaks } \\
\text { (Non-polar column) }\end{array}$} & \multirow{2}{*}{$\begin{array}{c}\begin{array}{c}\text { Number of peaks } \\
\text { (Polar column) }\end{array} \\
\text { Observed }\end{array}$} \\
\hline & & & & Observed & Predicted & $\begin{array}{c}\text { \% Difference } \\
\text { (CV) }\end{array}$ & \\
\hline 1 & 35 & 6 & 21 & 45 & 47 & 2.8 & 48 \\
\hline 2 & 55 & 6 & 21 & 37 & 39 & 3.6 & 66 \\
\hline 3 & 35 & 24 & 21 & 42 & 38 & 6.2 & 33 \\
\hline 4 & 55 & 24 & 21 & 31 & 31 & 1.1 & 42 \\
\hline 5 & 35 & 6 & 79 & 31 & 35 & 8.6 & 47 \\
\hline 6 & 55 & 6 & 79 & 21 & 27 & 17.9 & 72 \\
\hline 7 & 35 & 24 & 79 & 27 & 27 & 1.0 & 56 \\
\hline 8 & 55 & 24 & 79 & 12 & 19 & 30.8 & 39 \\
\hline 9 & 28 & 15 & 50 & 44 & 45 & 1.3 & 63 \\
\hline 10 & 62 & 15 & 50 & 38 & 31 & 13.3 & 59 \\
\hline 11 & 45 & 0 & 50 & 48 & 42 & 9.9 & 44 \\
\hline 12 & 45 & 30 & 50 & 27 & 28 & 1.5 & 54 \\
\hline 13 & 45 & 15 & 1 & 42 & 44 & 3.4 & 64 \\
\hline 14 & 45 & 15 & 99 & 32 & 24 & 19.6 & 43 \\
\hline 15 & 45 & 15 & 50 & 87 & 81 & 4.8 & 70 \\
\hline 16 & 45 & 15 & 50 & 80 & 81 & 1.2 & 68 \\
\hline 17 & 45 & 15 & 50 & 76 & 81 & 4.8 & 61 \\
\hline
\end{tabular}

CV - Coefficient of variation.

custard apple pulp resulted in reduced number of volatiles separated on non-polar column. In Pareto chart (Figure 3(b)), for number of peaks on polar column, the linear and quadratic effects of all parameters of SPME and their interactions were not significant $(\mathrm{p}>0.05)$.

From the data on experimental values presented in Table 4, the second order polynomial equation of fitted coded model for number of peaks on non-polar column (Equation (2)) was determined by regression analysis, where: $X_{1}$ is extraction temperature $\left({ }^{\circ} \mathrm{C}\right) ; X_{2}$ is sodium chloride amount (\%); and $X_{3}$ is pulp amount (\%). The fitted coded model was generated after exclusion of insignificant terms.

Furthermore, the significance of fitted model was evaluated by ANOVA (Table 5). This fitted model was highly significant $(\mathrm{p}<0.0001)$ for F-value calculated of 33.05, and its coefficient of determination $\left(\mathrm{R}^{2}\right)$ was 0.9520 . This model explains $95.20 \%$ of variations in dependent variable, and it accurately predicts the relationship between number of volatiles extracted from custard apple pulp 
a

(3) Pulp amount (\%) (L)
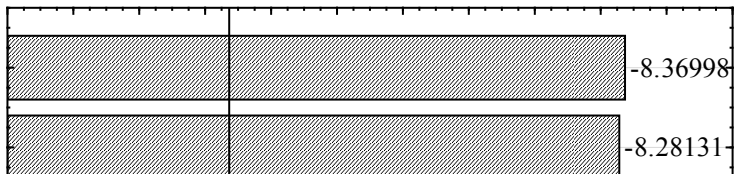

$-8.28131$

Extraction temperature $\left({ }^{\circ} \mathrm{C}\right)$

$=1$

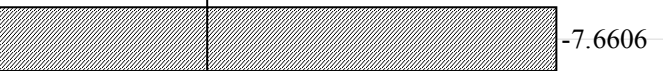

(2) $\mathrm{NaCl}(\%)(\mathrm{L})$

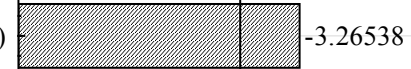

(2)

(1) Extraction temperature $\left({ }^{\circ} \mathrm{C}\right)(\mathrm{L})$

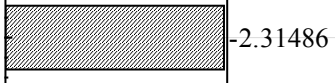

$1 \mathrm{~L}$ by $2 \mathrm{~L}$

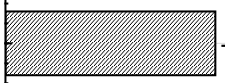

$-2.18554$

$1 \mathrm{~L}$ by $3 \mathrm{~L}$

$-.422231$

$2 \mathrm{~L}$ by $3 \mathrm{~L}$

$-.316673$

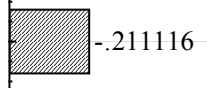

$\mathrm{p}=.05$

Standardized Effect Estimate (Absolute Value)

b
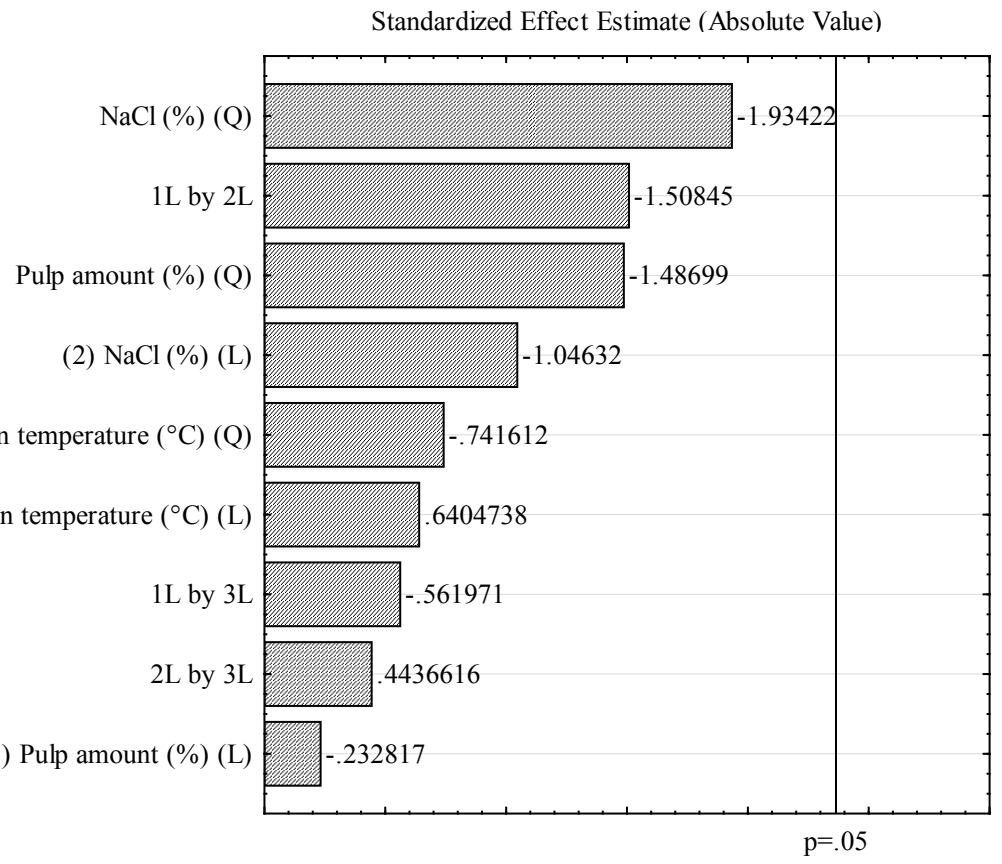

Standardized Effect Estimate (Absolute Value)

Figure 3. Pareto charts with their estimated effects for custard apple pulp volatiles. Response measured in (a) number of compounds on non-polar column, and (b) number of compounds on polar column.

Table 5. ANOVA for number of peaks of extracted of volatile compounds from custard apple pulp by SPME separated on non-polar column.

\begin{tabular}{cccccccc}
\hline Source of variation & SS & $\mathrm{df}$ & $\mathrm{MS}$ & $\mathrm{F}_{\text {calculated }}$ & $\mathrm{F}_{\text {tabulated }}$ & $\mathrm{p}$-value & $\mathrm{R}^{2}$ \\
\hline Regression & 6517.27 & 6 & 1086.21 & 33.05 & 3.22 & $<0.0001^{*}$ & 0.9520 \\
$X_{1}(\mathrm{~L})$ & 214.34 & 1 & 214.34 & 6.52 & 4.96 & $0.0287^{* *}$ & \\
$X_{1}(\mathrm{Q})$ & 2633.39 & 1 & 2633.39 & 80.14 & 4.96 & $<0.0001^{\star}$ &
\end{tabular}




\section{Continued}

\begin{tabular}{ccccccc}
\hline$X_{2}(\mathrm{~L})$ & 240.46 & 1 & 240.46 & 7.32 & 4.96 & $0.0221^{\star *}$ \\
$X_{2}(\mathrm{Q})$ & 3077.42 & 1 & 3077.42 & 93.65 & 4.96 & $<0.0001^{\star}$ \\
$X_{3}(\mathrm{~L})$ & 478.47 & 1 & 478.47 & 14.56 & 4.96 & $0.0034^{\star *}$ \\
$X_{3}(\mathrm{Q})$ & 3143.68 & 1 & 3143.68 & 95.66 & 4.96 & $<0.0001^{\star}$ \\
Lack of fit & 266.61 & 8 & 33.33 & 1.08 & 3.07 & $0.5667^{\text {ns }}$ \\
Pure error & 62.00 & 2 & 31.00 & - & - & - \\
Total & 6845.88 & 16 & - & - & - & - \\
\hline
\end{tabular}

SS - Sum of squares; df - Degrees of freedom; MS - Mean square; $\mathrm{R}^{2}$ - Coefficient of determination. $X_{1}$ - Extraction temperature $\left({ }^{\circ} \mathrm{C}\right) ; X_{2}$ - Sodium chloride concentration (\%); and $X_{3}$ - Pulp amount (\%). ${ }^{*} \mathrm{p}$ $\leq 0.001,{ }^{* *} \mathrm{p} \leq 0.05,{ }^{\mathrm{ns}} \mathrm{p}>0.05$ (not significant).

and SPME extraction parameters studied since lack of fit was not significant ( $\mathrm{p}>$ 0.05).

In Table 4, coefficients of variation below $25 \%$ indicate an acceptable dispersion between observed and predicted values hence showing a good precision of measurement and reproducibility of the model. The normal probability plot of residuals (Figure 4(a)) showed the points close to a diagonal line, which indicates that the error terms were normally distributed. Thus, the model was well fitted with experimental results. Ultimately, the plot of predicted versus observed values (Figure 4(b)) indicated an adequate agreement between the actual data and those generated by the fitted coded model, as previously mentioned.

\subsubsection{Influence of Extraction Temperature}

In headspace SPME techniques, the extraction time is an important parameter which influences the extraction yield. Since time affects the mass transfer of the analytes onto the fiber, optimum time is required for the fiber to reach equilibrium with headspace [34]. An increase in extraction temperature decreased the number of volatile compounds absorbed by DVB/CAR/PDMS fiber from custard apple pulp in headspace which was also observed in this work. One factor which influences these results is that higher temperatures affect adversely on the sorption of the analyte on the coating and consequently, extraction efficiency decreases when the extraction temperature increases [36].

It can be observed from the data presented in Table 4 that higher extraction temperatures $\left(55^{\circ} \mathrm{C}\right.$ and $\left.62^{\circ} \mathrm{C}\right)$ resulted in detection of lower number of volatile compounds, being $37,31,21,12$ and 38 peaks for the experiments $2,4,6,8$ and 10 , respectively, while for lower temperatures, the number of compounds were more, being higher number of compounds detected as 45, 42, 31, 27 and 44 peaks for the experiments 1, 3, 5, 7 and 9, respectively. However, the lowest temperature $\left(28^{\circ} \mathrm{C}\right)$ in SPME presented lower number of compounds, which may be because that the temperature was just insufficient for volatilization of organic compounds.

\subsubsection{Influence of Pulp Concentration}

According to the data presented in Table 4, it is observed that an increase in 

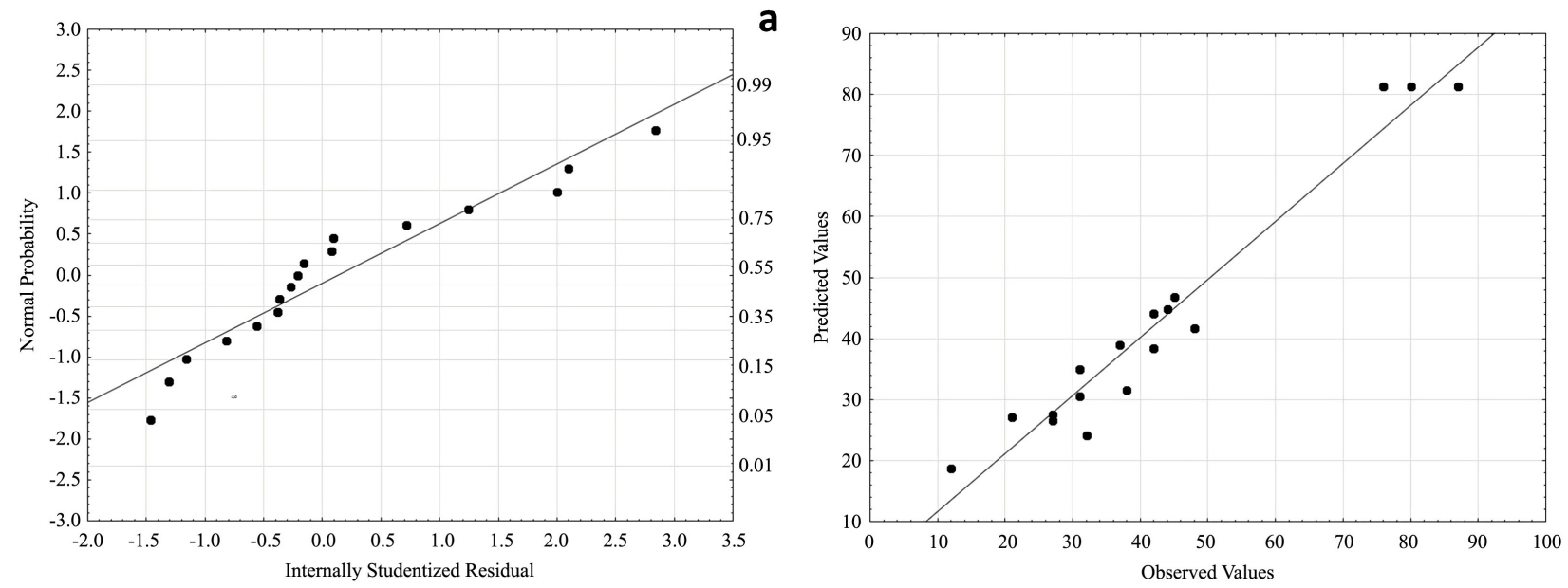

Figure 4. (a) Normal probability plot of residuals, and (b) Plot of predicted versus observed values of number of peaks of volatile compounds isolated from custard apple pulp by SPME.

pulp concentration over $50 \%$ has a negative effect on the absorption of volatile compounds present in pulp on to the fiber, i.e. higher the concentration of custard apple pulp, lower is the number of volatile compounds isolated. However, the increase in pulp concentration was related with an increase in the concentration of added sodium chloride which led to the saturation of the sample, whereby reducing the release of volatile compounds onto the headspace in vial. Thus on using pulp concentration of $79 \%$, the release of these volatiles decreases in the experiments with $24 \%$ sodium chloride (ionic strength) relative to the lowest sodium chloride concentration (6\%) at same extraction temperature.

\subsubsection{Influence of Ionic Strength}

The number of peaks decreased with increasing salt concentration. The exposure of the fiber at a concentration of $79 \%$ pulp at $35^{\circ} \mathrm{C}$ in which $6 \%$ and $24 \%$ of salt were used (experiments 5 and 7), resulted in the separation of 31 and 27 peaks, respectively. However, when the extraction was performed at $45^{\circ} \mathrm{C}$ having the same salt concentration ( $0 \%$ and 15\%) in experiment numbers 11 and 15, 48 and 87 peaks were separated, respectively.

Among all the experiments carried out, the experiment number 10 which utilized higher temperature $\left(62^{\circ} \mathrm{C}\right)$ for extraction but had lower salt $(15 \%)$ and pulp concentrations $(50 \%)$ resulted in a lower number (38) of peaks which reveals that the interactions between these parameters were not significant, i.e. one parameter does not influence the other, demonstrating the detrimental effect of temperature and concentration of the sample. The Pareto chart (Figure 3(a)) shows this effect at the significance level of $5 \%$.

Among all the experiments performed, those in center point conditions of independent variables resulted in the isolation of a higher number (81) of compounds on the non-polar column. Thus, the best conditions for SPME technique, proven through this experimental design, were defined as the use of 50\% pulp; $15 \% \mathrm{NaCl} ; 45^{\circ} \mathrm{C}$ of temperature of this experiment which had the maximum 
number of volatile compounds separated in gas chromatography system coupled to high resolution mass spectrometry.

The exposure time of the fiber in injector of gas chromatograph for desorption of analytes is also an important factor. This would be another variable worth analyzing, although, it is known that the desorption occurs in a very short period of time. The fiber exposure time in the injector for all experiments was 7 min, which is much higher than required for desorption. In addition, desorption of fiber was performed in GC injector between the chromatographic analyses in order to check the "memory effect" of the fiber, i.e., if a small amount of analyte was not desorbed it may interfere in the subsequent analyses. This phenomenon was not observed in any of the tests performed, concluding that the 7 min exposure time was good enough for complete desorption.

\subsubsection{Optimization of SPME Technique and Model Validation}

Optimization aims to find SPME conditions which, results in isolation of a maximum number of peaks of volatile compounds from custard apple pulp. Response surface plots in Figures 5(a)-(c) show the interaction effects of independent variables in pairs. For optimization it is necessary to combine these conditions in a single test that maximizes response variable. The optimized conditions of SPME for extraction of volatiles from custard pulp were: $45^{\circ} \mathrm{C}$ of extraction temperature, sodium chloride concentration of $15 \%$ and pulp amount of $50 \%$. In these optimized conditions, the predicted number of peaks was approximately 81 by fitted coded model.

Additionally, validation of the model was performed from experiments using $50 \%$ pulp, addition of $15 \%$ sodium chloride and volatiles isolation realized in vial containing $10 \mathrm{~mL}$ aliquot at $45^{\circ} \mathrm{C}$ for $30 \mathrm{~min}$ using DVB/CAR/PDMS fiber and separation performed in GC. The number of peaks of these experiments ranged from 72 to 82 . Predicted and observed mean values were 81 and 78, respectively, in these extraction conditions, for which coefficient of variation (CV) was low (3.0\%) which indicates also the suitability and accuracy of the model (Table 6).

\section{Conclusions}

Among several fibers used in SPME, the results reveal that the DVB/CAR/PDMS fiber was most efficient for the isolation of terpenes for custard apple fruit volatile compounds. The optimum conditions were $45^{\circ} \mathrm{C}$ for extraction, $15 \%$ of sodium

Table 6. Validation of fitted coded model to the number of extracted volatile compounds by SPME from custard apple pulp as a function of extraction temperature $\left({ }^{\circ} \mathrm{C}\right)$, sodium chloride concentration (\%) and pulp amount (\%).

\begin{tabular}{cccccc}
\hline \multirow{2}{*}{$\begin{array}{c}\text { Extraction } \\
\text { temperature }\left({ }^{\circ} \mathrm{C}\right)\end{array}$} & \multirow{2}{*}{$\begin{array}{c}\mathrm{NaCl} \\
(\%)\end{array}$} & $\begin{array}{c}\text { Pulp amount } \\
(\%)\end{array}$ & \multicolumn{3}{c}{ Number of peaks on non-polar column } \\
\cline { 5 - 6 } & & & Predicted & Observed & \% Difference (CV) \\
\hline 45 & 15 & 50 & 81 & $78 \pm 5$ & 3.0 \\
\hline
\end{tabular}

CV-Coefficient of variation. 

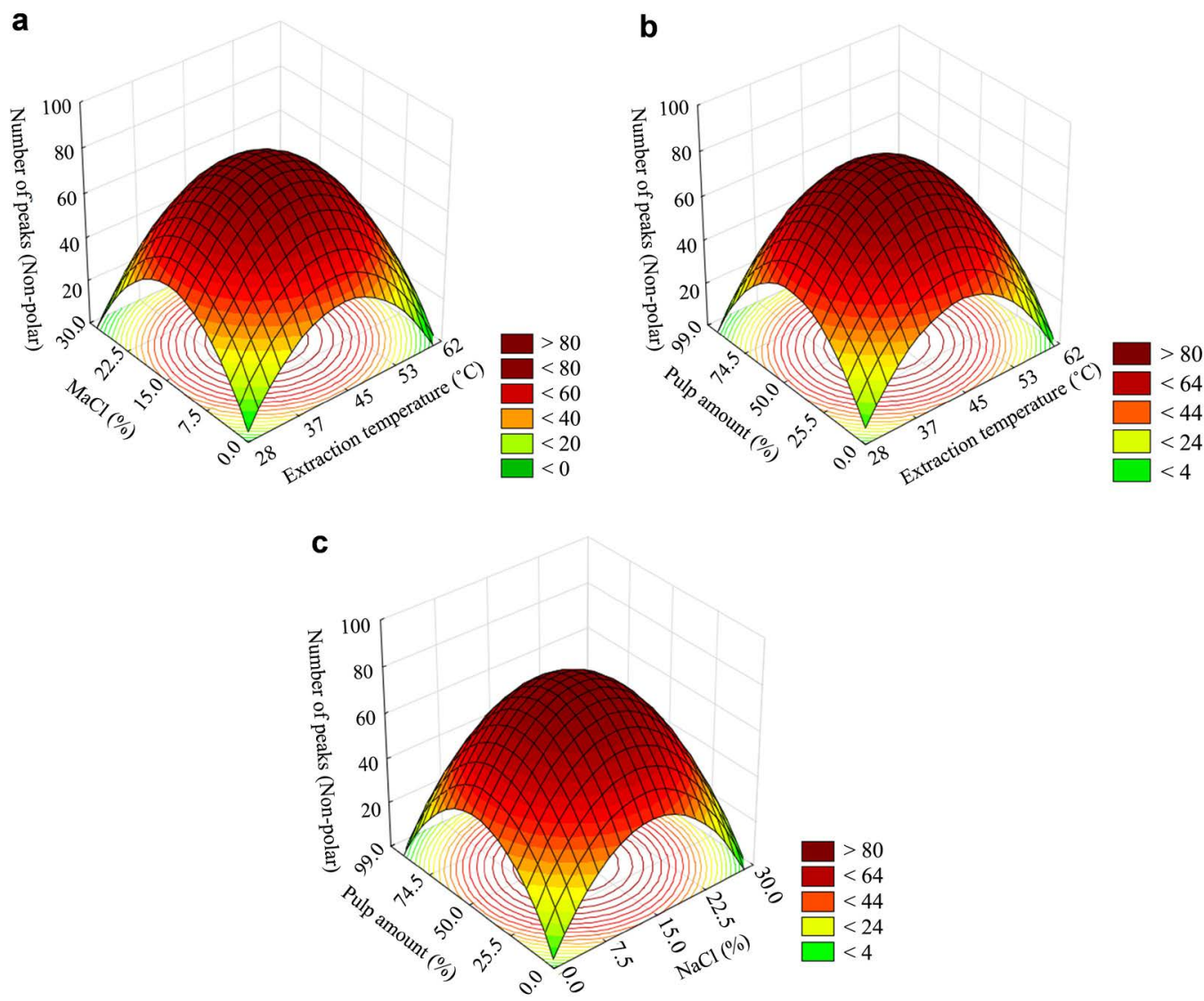

Figure 5. (a) Interaction effects of extraction temperature and sodium chloride amount, (b) Interaction effects of extraction temperature and pulp amount, (c) Interaction effects of sodium chloride amount and pulp amount towards the number of peaks from custard apple pulp using response surface methodology.

chloride and $50 \%$ of pulp amount which resulted in a maximum of 87 peaks. The main compounds found in custard apple fruit were: $\alpha$-pinene, $\beta$-pinene, limonene, (E)- $\beta$-ocimene, (-)- $\beta$-pinene, D-germacrene, and $\lambda$-elemene. Forty compounds have not been reported earlier and their presence in custard apple pulp is being reported for the first time in this study, which includes also (-)- $\beta$-pinene and $\lambda$-elemene. Further studies about the volatile composition of the custard apple are necessary to better understand the aroma of this fruit, extraction alternatives, for example, the SBSE technique can also be very attractive for a better elucidation on the volatile composition.

\section{Funding}

This study was funded by Conselho Nacional de Desenvolvimento Científico e Tecnológico (CNPq) vide research 3999 (Process 57573781/2008-7).

\section{Ethical Approval}

This article does not contain any studies with human or animal subjects performed by any of the authors. 


\section{Conflicts of Interest}

All authors of this work declare that they have no conflict of interest.

\section{References}

[1] Dembitsky, V.M., Poovarodom, S., Leontowicz, H., et al. (2011) The Multiple Nutrition Properties of Some Exotic Fruits: Biological Activity and Active Metabolites. Food Research International, 44, 1671-1701. https://doi.org/10.1016/j.foodres.2011.03.003

[2] Li, C., Feng, J., Huang, W.-Y. and An, X.-T. (2013) Composition of Polyphenols and Antioxidant Activity of Rabbiteye Blueberry (Vaccinium ashei) in Nanjing. Journal of Agricultural and Food Chemistry, 61, 523-531. https://doi.org/10.1021/jf3046158

[3] Silva, L.M.R., Figueiredo, E.A.T., Ricardo, N.M.P.S., et al. (2014) Quantification of Bioactive Compounds in Pulps and By-Products of Tropical Fruits from Brazil. Food Chemistry, 143, 398-404. https://doi.org/10.1016/j.foodchem.2013.08.001

[4] Shashirekha, M.N., Baskaran, R. and Jaganmohan, L. (2008) Influence of Processing Conditions on Flavour Compounds of Custard Apple (Annona squamosa L.). LWT-Food Science and Technology, 41, 236-243. https://doi.org/10.1016/j.lwt.2007.03.005

[5] Abdualrahman, M.A.Y., Ma, H., Zhou, C., et al. (2019) Postharvest Physicochemical Properties of the Pulp and Seed Oil from Annona squamosa L. (Gishta) Fruit Grown in Darfur Region, Sudan. Arabian Journal of Chemistry, 12, 4514-4521.

[6] Andrade, E.H.A., Zoghbi, M. das, G.B., Maia, J.G.S., et al. (2001) Chemical Characterization of the Fruit of Annona squamosa L. Occurring in the Amazon. Journal of Food Composition and Analysis, 14, 227-232. https://doi.org/10.1006/jfca.2000.0968

[7] Pelissier, Y., Marion, C., Dezeuze, A. and Bessiere, J. (1993) Volatile Components of Annona squamosa L. Journal of Essential Oil Research, 5, 557-560. https://doi.org/10.1080/10412905.1993.9698278

[8] Wong, K.C. and Khoo, K.H. (1993) Volatile Components of Malaysian Annona Fruits. Flavour and Fragrance Journal, 8, 5-10. https://doi.org/10.1002/ffj.2730080103

[9] Wyllie, S.G., Cook, D., Brophy, J.J. and Richter, K.M. (1987) Volatile Flavor Components of Annona atemoya (Custard Apple). Journal of Agriculture and Food Chemistry, 35, 768-770. https://doi.org/10.1021/jf00077a029

[10] Ouyang, G. (2012) Calibration. In: Handbook of Solid Phase Microextraction, Elsevier, Amsterdam, 167-199. https://doi.org/10.1016/B978-0-12-416017-0.00006-1

[11] Koziel, J.A. and Novak, I. (2002) Sampling and Sample-Preparation Strategies Based on Solid-Phase Microextraction for Analysis of Indoor Air. Trends in Analytical Chemistry, 21, 840-850. https://doi.org/10.1016/S0165-9936(02)01204-9

[12] Vesely, P., Lusk, L., Basarova, G., et al. (2003) Analysis of Aldehydes in Beer Using Solid-Phase Microextraction with On-Fiber Derivatization and Gas Chromatography/Mass Spectrometry. Journal of Agriculture and Food Chemistry, 51, 6941-6944. https://doi.org/10.1021/jf034410t

[13] Deng, J., Yang, Y., Wang, X. and Luan, T. (2014) Strategies for Coupling Solid-Phase Microextraction with Mass Spectrometry. Trends in Analythical Chemistry, 55, 55-67. https://doi.org/10.1016/j.trac.2013.12.004

[14] Kataoka, H., Lord, H.L. and Pawliszyn, J. (2000) Applications of Solid-Phase Mi- 
croextraction in Food Analysis. Journal of Chromatography A, 880, 35-62. https://doi.org/10.1016/S0021-9673(00)00309-5

[15] Kataoka, H. (2017) Sample Preparation for Liquid Chromatography. In: Liquid Chromatography, Elsevier, Amsterdam, 1-37. https://doi.org/10.1016/B978-0-12-805392-8.00001-3

[16] Mehta, P.K., de Sousa Galvão, M., Soares, A.C., et al. (2018) Volatile Constituents of Jambolan (Syzygium cumini L.) Fruits at Three Maturation Stages and Optimization of HS-SPME GC-MS Method Using a Central Composite Design. Food Analythical Methods, 11, 733-749. https://doi.org/10.1007/s12161-017-1038-4

[17] Zhang, F., Zhan, P., Tian, H., et al. (2018) Optimization of HS-SPME Using Artificial Neural Network and Response Surface Methodology in Combination with Experimental Design for Determination of Volatile Components by Gas Chromatography-Mass Spectrometry in Korla Pear Juice. Food Analythical Methods, 11, 2218-2228. https://doi.org/10.1007/s12161-018-1173-6

[18] Cheong, K.W., Tan, C.P., Mirhosseini, H., et al. (2011) Optimization of Equilibrium Headspace Analysis of Volatile Flavor Compounds of Malaysian Soursop (Annona muricata): Comprehensive Two-Dimensional Gas Chromatography Time-of-Flight Mass Spectrometry (GC×GC-TOFMS). Food Chemistry, 125, 1481-1489. https://doi.org/10.1016/j.foodchem.2010.10.067

[19] Santana, K.L., Galvão, M.S., Jesus, M.S., et al. (2017) HS-SPME Optimization and Extraction of Volatile Compounds from Soursop (Annona muricata L.) Pulp with Emphasis on Their Characteristic Impact Compounds. Food Science and Technology, 37, 250-260. https://doi.org/10.1590/1678-457x.20916

[20] Chmiel, T., Kupska, M., Wardencki, W. and Namieśnik, J. (2017) Application of Response Surface Methodology to Optimize Solid-Phase Microextraction Procedure for Chromatographic Determination of Aroma-Active Monoterpenes in Berries. Food Chemistry, 221, 1041-1056. https://doi.org/10.1016/j.foodchem.2016.11.057

[21] D’Agostino, M.F., Sanz, J., Martínez-Castro, I., et al. (2014) Statistical Analysis for Improving Data Precision in the SPME GC-MS Analysis of Blackberry (Rubus ulmifolius Schott) Volatiles. Talanta, 125, 248-256. https://doi.org/10.1016/j.talanta.2014.02.058

[22] Myers, R.H., Montgomery, D.C. and Anderson-Cook, C.M. (2016) Response Surface Methodology: Process and Product Optimization Using Designed Experiments. 4th Edition, John Wiley \& Sons, Inc., Hoboken.

[23] Carabajal, M., Teglia, C.M., Cerutti, S., et al. (2020) Applications of Liquid-Phase Microextraction Procedures to Complex Samples Assisted by Response Surface Methodology for Optimization. Microchemical Journal, 152, Article ID: 104436. https://doi.org/10.1016/j.microc.2019.104436

[24] Galvão, M.S., Narain, N., dos Santos, M.S.P. and Nunes, M.L. (2011) Volatile Compounds and Descriptive Odor Attributes in Umbu (Spondias tuberosa) Fruits during Maturation. Food Research International, 44, 1919-1926.

[25] NIST (2011) NIST Standard Reference Database 69: NIST Chemistry WebBook. Secr. Commer. Behalf United States Am. http://webbook.nist.gov

[26] Jennings, W.G. and Shibamoto, T. (1980) Qualitative Analysis of Flavor and Fragrance Volatiles by Glass Capillary Gas Chromatography. Academic Press, San Francisco.

[27] Adams, R.P. (1989) Identification of Essential Oils by Ion Trap Mass Spectroscopy. Academic Press, New York. https://doi.org/10.1016/B978-0-12-044230-0.50005-8

[28] Kondjoyan, N. and Berdague, J.-L. (1996) A Compilation of Relative Retention Indices for the Analysis of Aromatic Compounds. Laboratoire Flaveur, Cler- 
mont-Ferrand.

[29] Roberts, D.D., Pollien, P. and Milo, C. (2000) Solid-Phase Microextraction Method Development for Headspace Analysis of Volatile Flavor Compounds. Journal of Agricultural and Food Chemistry, 48, 2430-2437. https://doi.org/10.1021/jf9911161

[30] Soares, R.D., Welke, J.E., Nicolli, K.P., et al. (2015) Monitoring the Evolution of Volatile Compounds Using Gas Chromatography during the Stages of Production of Moscatel Sparkling Wine. Food Chemistry, 183, 291-304. https://doi.org/10.1016/j.foodchem.2015.03.013

[31] Ceva-Antunes, P.M.N., Bizzo, H.R., Silva, A.S., et al. (2006) Analysis of Volatile Composition of Siriguela (Spondias purpurea L.) by Solid Phase Microextraction (SPME). LWT-Food Science and Technology, 39, 437-443. https://doi.org/10.1016/j.lwt.2005.02.007

[32] Augusto, F., Luiz, A., Valente, P., et al. (2000) Screening of Brazilian Fruit Aromas Using Solid-Phase Microextraction-Gas Chromatography-Mass Spectrometry. Journal of Chromatography A, 873, 117-127. https://doi.org/10.1016/S0021-9673(99)01282-0

[33] Acree, T.E. and Arn, H. (2004) Flavornet and Human Odor Space. http://www.flavornet.org/flavornet.html

[34] Arctander, S. (1969) Perfume and Flavor Chemicals (Aroma Chemicals). Montclair, Newark.

[35] Pontes, M., Marques, J.C. and Câmara, J.S. (2009) Headspace Solid-Phase Microextraction-Gas Chromatography-Quadrupole Mass Spectrometric Methodology for the Establishment of the Volatile Composition of Passiflora Fruit Species. Microchemical Journal, 93, 1-11. https://doi.org/10.1016/j.microc.2009.03.010

[36] Setkova, L., Risticevic, S. and Pawliszyn, J. (2007) Rapid Headspace Solid-Phase Microextraction-Gas Chromatographic-Time-of-Flight Mass Spectrometric Method for Qualitative Profiling of Ice Wine Volatile Fraction II: Classification of Canadian and Czech Ice Wines Using Statistical Evaluation of the Data. Journal of Chromatography $A, 1147,224-240$. https://doi.org/10.1016/j.chroma.2007.02.058 